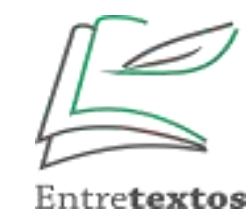

Entretextos 21(3): especial, 2021

ISSN (digital): 2764-0809

ISSN (impresso): 1519-5392

DOI: $10.5433 / 1519-5392.2021 v 21 n 3 E s p . p 5$

\title{
Português como LE/L2 na UFSCar: Mapeando os registros sobre extensão, ensino e pesquisa
}

\author{
Portuguese as FL/L2 at UFSCar: Mapping the records on extension, \\ teaching and research
}

\section{Portugués como LE/L2 en la UFSCar: Mapeando los registros sobre extensión, enseñanza e investigación}

\author{
Matheus Granato ${ }^{1}$ (iD) https://orcid.org/0000-0002-7210-6328 \\ Rosa Yokota ${ }^{2}$ (D) https://orcid.org/0000-0002-1672-1430
}

\begin{abstract}
RESUMO: Neste artigo, apresenta-se mapeamento das atividades de extensão, ensino e pesquisa na área de Português como Língua Estrangeira e como Segunda Língua (PLE/L2) realizadas na Universidade Federal de São Carlos (UFSCar). O estudo visa contribuir para a compreensão do processo de institucionalização da área na UFSCar e do impacto de políticas linguísticas nacionais relacionadas com o PLE/L2 no âmbito local da instituição, a partir das contribuições de Furtoso (2015); Rocha (2019); Bulla, Kuhn (2020); Brasil (2021); Scaramucci, Bizon (2020). Para tanto, fez-se um levantamento das ações documentadas sobre a extensão, o ensino e a pesquisa de 1994 a 2021, além da busca pelas pesquisas de graduação e pósgraduação disponibilizadas no Repositório Institucional (RI) da universidade. Verificou-se que, na UFSCar, as atividades de extensão iniciaram as ações na área de PLE/L2, que houve a incorporação do seu ensino no âmbito da formação de professores e de tradutores-intérpretes de libras e que a pesquisa sobre o tema acompanhou a expansão dos cursos de graduação e pósgraduação na instituição.
\end{abstract}

PALAVRAS-CHAVE: Português como LE/L2. Produção científica. Extensão universitária.

ABSTRACT: This paper presents a mapping of extension, teaching, and research activities in Portuguese as a Foreign Language and as a Second Language (PFL/SL) carried out at the Universidade Federal de São Carlos (UFSCar). In addition to the bibliographic research, there was a search for undergraduate and graduate research made available in the university's Institutional

\footnotetext{
${ }^{1}$ Licenciado em Letras - Português e Espanhol pela UFSCar. Mestrando em Linguística e Língua Portuguesa pela FCL/UNESP, câmpus de Araraquara. E-mail: matheus.granato@unesp.br

${ }^{2}$ Doutora em Letras - USP. Docente do Departamento de Letras e do Programa de Pós-Graduação em Linguística da UFSCar. E-mail: ryokota@ufscar.br
} 
Repository (IR). The study aims to contribute to the understanding of the institutionalization process of the area at UFSCar and the impact of national language policies related to PFL/SL at the local level of the institution, based on the contributions of Furtoso (2015), Rocha (2019), Bulla; Kuhn (2020), Brasil (2021), Bizon; Scaramucci (2020). To this end, there was a survey of documented actions on extension, teaching, and research from 1994 to 2021 . We verified that, at UFSCar, PFL/SL started through extension activities, and there was also the incorporation of its teaching into the training of teachers and translators-interpreters of Libras (Brazilian Sign Language), and that research on the subject followed the expansion of undergraduate and graduate courses in the institution.

KEYWORDS: Portuguese as FL/SL. Scientific production. University extension.

RESUMEN: En este artículo se presenta un mapeo de actividades de extensión, enseñanza e investigación en el área de Portugués como Lengua Extranjera y como Segunda Lengua (PLE/L2) llevadas a cabo en la Universidade Federal de São Carlos (UFSCar). Además del estudio bibliográfico, se realizó una búsqueda por las investigaciones de pregrado y posgrado disponibles en el Repositório Institucional (RI) de la universidad. El estudio pretende contribuir con la comprensión del proceso de institucionalización del área en la UFSCar y del impacto de las políticas lingüísticas nacionales relativas al PLE/L2 en el ámbito local de la institución, a partir de las contribuciones de Furtoso (2015), Rocha (2019), Bulla; Kuhn (2020), Brasil (2021), Bizon; Scaramucci (2020). Para ello, se hizo una recogida de las acciones documentadas sobre la extensión, la enseñanza y la investigación de 1994 a 2021. Se constató que las actividades de extensión iniciaron las acciones en el área de PLE/L2 en la UFSCar, que se incorporó su enseñanza en el ámbito de la formación de profesores y de traductores-intérpretes de libras (lengua de señas brasileña) y que la investigación sobre el tema ha acompañado la expansión de los cursos de pregrado y de posgrado en la institución.

PALABRAS CLAVE: Portugués como LE/L2. Producción científica. Extensión universitaria.

\section{Introdução}

Neste artigo, pretende-se discurtir a implementação e institucionalização da área de Português como Língua Estrangeira e Segunda Língua (PLE/L2) ${ }^{3}$ na Universidade Federal de São Carlos (UFSCar) ${ }^{4}$, a partir de um duplo movimento: de um lado, a apresentação de um histórico de ações de ensino, extensão e política linguística relacionadas ao PLE/L2 promovidas na instituição; de outro, o mapeamento de pesquisas sobre o tema registradas no seu repositório institucional.

\footnotetext{
${ }^{3}$ Como observam Bulla; Kuhn (2020) e Rocha (2019), a área tem sido nomeada de diferentes formas no Brasil: "Português como Língua Adicional", "Português para Falantes de outras Línguas", "Português como Língua não Materna", "Português como Língua de Herança", "Português como Língua de Acolhimento", dentre outras, propostas a partir de contextos de atuação e abordagens epistemológicas específicos. Neste trabalho, optamos pelos termos "Português como Língua Estrangeira" e "Português como Segunda Língua" por conta de sua abrangência e tradição (ROCHA, 2019) e em consonância à nomenclatura que tem sido mais empregada pelos pesquisadores da área na UFSCar.

${ }^{4}$ A Universidade Federal de São Carlos (UFSCar, 2018) é a única universidade federal atuante no interior do Estado de São Paulo. Foi instituída pelo Decreto de lei no 62.758, de 23 de maio de 1968, e teve suas atividades iniciadas no ano de 1970 em São Carlos-SP. Atualmente promove atividades de ensino, pesquisa e extensão em quatro campi, nos municípios paulistas de Araras, Buri (fazenda Lagoa do Sino), São Carlos e Sorocaba, somando mais de 26.000 estudantes em seus cursos de graduação e pós-graduação.
} 
Busca-se enfatizar a importância das políticas linguísticas e públicas relacionadas com o ensino do PLE/L2 no âmbito nacional e seus impactos na UFSCar, sendo um dos resultados a produtividade acadêmica registrada através de pesquisas de graduação e pós-graduação.

O texto está dividido em quatro seções, mais as considerações finais. Na primeira seção apresentamos um histórico das ações na área de PLE/L2 na UFSCar. Na segunda seção, focamos nas atividades de pesquisa e descrevemos os procedimentos adotados para o mapeamento de publicações no Repositório Institucional (RI) da universidade. $\mathrm{Na}$ terceira seção, versamos sobre os critérios de organização e classificação dos dados. $\mathrm{Na}$ quarta seção apresentamos os resultados do mapeamento empreendido relacionando-os às ações de extensão e ensino apresentadas.

\section{O PLE/L2 na UFSCar}

A área de PLE/L2 tem passado, nas últimas décadas, por um crescente processo de institucionalização nas instituições de ensino superior brasileiras. Este processo foi iniciado ainda nos anos de 1960 e 1970 pela oferta de cursos de PLE em algumas universidades ${ }^{5}$ como consequência das demandas internas das instituições e de ações de política linguística nacionais como a criação dos Centros Culturais Brasileiros ${ }^{6}$, do Programa de Leitorado 7 e do Programa de Estudantes Convênio de Graduação (PEC-G) ${ }^{8}$ (BRASIL, 2021, p. 169-182). Particularmente a partir da década de 1990, como destaca Rocha (2019), tem-se um importante fortalecimento da área enquanto campo de atuação e pesquisa, propiciado pela criação de associações científicas ${ }^{9}$, de eventos acadêmicos ${ }^{10}$,

\footnotetext{
${ }^{5}$ Tais como a Universidade Federal da Bahia (UFBA), a Pontificia Universidade Católica do Rio grande do Sul (PUCRS), a Universidade de Campinas (Unicamp), a Universidade Federal de Minas Gerais (UFMG), a Universidade Federal do Rio de Janeiro (UFRJ) e a Universidade de São Paulo (USP), pioneiras nesse processo (BRASIL, 2021, p. 169).

${ }^{6}$ Os Centros Culturais Brasileiros (CCBs) são extensões das embaixadas brasileiras no exterior, com atuação voltada para a promoção da língua portuguesa, em sua variedade brasileira, e outras atividades culturais. A origem dos CCBs remonta à década de 1930, embora só em 1950 haja uma maior atuação do estado para o seu fortalecimento (BRASIL, 2021, 107-123). Atualmente conta-se com 24 CCBs: 6 na África, 13 na América, 3 na Europa e 2 no Oriente Médio.

${ }^{7} \mathrm{O}$ Leitorado é um programa do Ministério de Relações Exteriores, existente desde a década de 1950, que promove a atuação de professores brasileiros em universidades do exterior para a promoção e ensino da língua, literatura e cultura.

${ }^{8}$ O Programa de Estudantes-Convênio de Graduação (PEC-G), atualmente promovido pelo Ministério de Relações Exteriores, é o mais antigo programa institucional brasileiro para recepção de estrangeiros em mobilidade acadêmica, criado em 1965 pelo Decreto de lei no 55.613.

${ }^{9}$ Destaca-se a criação da Sociedade Internacional de Português Língua Estrangeira (SIPLE) em 1992.

${ }^{10} \mathrm{O}$ primeiro evento acadêmico na área foi realizado na Unicamp, em 1979 (BRASIL, 2021, p. 171).
} 
do exame CELPE-Bras ${ }^{11}$, de cursos de licenciatura específicos na área ${ }^{12}$, além do aumento na publicação de materiais didáticos e textos acadêmicos ${ }^{13}$.

Na UFSCar, assim como em outras instituições de ensino superior brasileiras (BULLA; KUHN, 2020; FURTOSO, 2015; SCARAMUCCI; BIZON 2020), a implantação do PLE/L2 se deu a partir de atividades extensionistas. Como registrado por Barbosa (1996), a primeira ação na área na UFSCar ocorreu em 1994, antes mesmo da criação dos cursos de Licenciatura em Letras na instituição ${ }^{14}$, em resposta a uma demanda da administração superior da universidade para que o Departamento de Letras $(D L)^{15}$ oferecesse formação linguística em língua portuguesa a um grupo de estudantes francófonos que cursavam disciplinas no curso de Engenharia de Materiais pelo programa PEC-G.

Desde essa experiência, docentes do $D L$ têm dado continuidade à formação em língua portuguesa para estrangeiros na UFSCar por meio de ações de política e planejamento linguísticos na extensão, no ensino e na pesquisa, vinculadas ao Centro de Referência em Português para Estrangeiros (Cerepe), localizado no DL. Nesses mais de 25 anos, as ações do Cerepe têm atendido estudantes intercambistas, estrangeiros da comunidade externa ${ }^{16}$, imigrantes de crise e refugiados da região.

Como contribuição importante da universidade em ações interinstitucionais de gestão e difusão do PLE/L2, destaca-se a recepção da Sociedade Internacional de Português Língua Estrangeira (SIPLE), sediada no DL no biênio 2005-2007, tendo três docentes da casa como membros da diretoria: Nelson Viana (presidente), Mônica Baltazar Diniz Signori (primeira tesoureira) e Lúcia Maria de Assunção Barbosa (primeira

\footnotetext{
${ }^{11}$ Certificado de Proficiência em Língua Portuguesa para Estrangeiros (Celpe-Bras), criado em 1994 e aplicado desde 1998. É o único exame de proficiência no idioma reconhecido pelo estado brasileiro.

${ }^{12}$ Atualmente são quatro as instituições com cursos de graduação na área: a Universidade de Brasília (desde 1998), a UFBA (desde 2005), a Universidade Federal da Integração Latinoamericana (desde 2015) e a Unicamp (desde 2017). ${ }^{13}$ As primeiras publicações acadêmicas sobre o PLE/L2 no Brasil datam da década de 1980. Destacam-se a dissertação de Arai (1985), como primeiro trabalho de pós-graduação na área (FURTOSO, 2015), o artigo de Baleeiro; El-Dash; Lombello (1983) e a coletânea organizada por Almeida Filho e Lombello (1989).

${ }^{14} \mathrm{O}$ curso de Licenciatura em Letras da UFSCar, ofertado no campus de São Carlos, foi criado pela Resolução ConsUni no 244, de 13 de junho de 1995. O início de suas atividades foi em 1996. Tem cinco anos de duração e oferta 40 vagas anuais, 20 na habilitação em Espanhol, Português e suas respectivas literaturas, e 20 em Inglês, Português e suas respectivas literaturas. Atualmente, reconhecem-se como dois cursos distintos: Letras - Português e Espanhol, Letras - Português e Inglês.

${ }^{15}$ O DL foi instituído em 1989, vinculado ao Centro de Educação e Ciências Humanas, alocando docentes responsáveis por disciplinas na área de linguagens, oferecidas na instituição desde a década de 1970 (UFSCar, 2020, p. 7). Além dos cursos de Letras, o DL é responsável pela oferta do curso de Bacharelado em Linguística, criado em 2009, e uma parcela de seus docentes integram os programas de pós-graduação em Linguística (PPGL), criado em 2005, e em Estudos de Literatura (PPGLit), criado em 2011, ambos com cursos de mestrado e doutorado.

${ }^{16} \mathrm{O}$ trabalho de Morilas (2003), por exemplo, registra a experiência de oferta de cursos de português a adolescentes coreanos que vieram a São Carlos-SP no início dos anos 2000 para estudar e praticar futebol em um projeto municipal. Mais recentemente, os cursos de PLE/L2 da instituição têm recebido também estudantes dos campi da Universidade de São Paulo (USP) em São Carlos e profissionais estrangeiros que vêm atuar na região.
} 
secretária). Nesse período, realizou-se na UFSCar o VII Seminário SIPLE, em 2005, com o tema "Dimensões teórico-práticas e institucionais das experiências de ensinar e aprender português como língua estrangeira" (VIANA, 2019), e o VI Congresso Internacional da SIPLE, em 2007, com o tema "Vertentes culturais no ensino de português língua estrangeira"17.

A UFSCar teve papel de destaque também na criação do Núcleo Disciplinar PELSE (Ensino de Espanhol e Português como Segunda Língua e Língua Estrangeira), da Associação de Universidades Grupo de Montevideo (AUGM), tendo Nelson Viana como seu primeiro presidente e sediando, em 2009, o I Colóquio PELSE (ASOCIACIÓN DE UNIVERSIDADES GRUPO MONTEVIDEO, ([2021]).

Também em 2009, a universidade se tornou posto aplicador do exame CelpeBras, sendo um dos únicos três postos aplicadores do exame no estado de $\mathrm{SP}$, junto à Unicamp (Campinas) e à UMESP (São Bernardo do Campo) (CELPE-BRAS, 2019). A partir de 2011, o preparatório para o exame passou a ser parte do catálogo de cursos oferecidos pelo Cerepe.

No período de 2011 a 2016, os cursos do Cerepe receberam um total de 854 inscrições de estudantes estrangeiros, provenientes de 67 nações, dos cinco continentes (GÓMEZ, 2018, p. 112). A partir de 2017, o Núcleo de Línguas (Nucli/IsF) da UFSCar também passou a ofertar cursos de PLE com fins específicos e, a partir de 2018, os cursos antes ofertados pelo Cerepe passaram a ser promovidos pelo Instituto de Línguas da UFSCar (IL) ${ }^{18}$, que teve inscrição de 229 estudantes estrangeiros entre 2018 e 2019 e de 46 (oferta remota) no segundo semestre de $2020^{19}$, durante a pandemia de covid-19.

Ressalta-se que a implantação do Nucli/IsF é uma ação relacionada à política de internacionalização das universidades públicas pelo governo brasileiro, inicialmente motivada pela necessidade de oferta de cursos de inglês para fins específicos como forma de apoiar o projeto Ciências sem Fronteiras, do Ministério da Educação e Cultura. A partir de 2014, o PLE passou a integrar o rol de línguas abarcadas pelo Idiomas sem Fronteiras (IsF) e, por meio da Portaria n030/2016, que amplia o programa, ratificou-se como um de seus objetivos centrais o fortalecimento do ensino de língua portuguesa do Brasil e da

${ }^{19}$ Dados do relatório do IL, de 29 de setembro de 2020, para a transição da gestão universitária. 
cultura brasileira no exterior. Em 2017, pelo Edital n029, o IsF passou a analisar o documento de políticas linguísticas da instituição e a fomentar, por meio de sua política de aporte financeiro, a inclusão do PLE como um dos idiomas a serem oferecidos pelas instituições credenciadas (BRASIL, 2021, p. 157-158).

No âmbito institucional, a UFSCar cria o IL em 2016, com o objetivo de "desenvolver, acompanhar e avaliar as políticas linguísticas implementadas pela UFSCar, reconhecendo demandas de formação e planejando ações para a disseminação do conhecimento de línguas e culturas" (UFSCar, 2020, p. 6), tendo cinco áreas de atuação: Língua de sinais brasileira (libras); Língua espanhola; Língua inglesa; Língua portuguesa (materna ou estrangeira); Literaturas. É justamente no contexto do IL que se tem, no ano de 2018, a abertura do primeiro concurso da instituição com vaga específica para docente na área de PLE, por meio do Edital n008/2018: uma vaga de professor visitante, aberta para um contrato de dois anos, com objetivo de fortalecer as atividades de extensão, ensino e pesquisa em PLE/L2 na UFSCar.

No DL, foi a partir de 2019, por meio da reformulação do Regimento Interno do departamento, aprovada no dia 08 de maio de 2019, que o "Português Língua Estrangeira" passa a ser reconhecido como uma de suas áreas, junto a outras quatro 20 que existem desde a criação do curso de Letras. A área de PLE no DL é coordenada e integrada por apenas um docente, Nelson Viana, que faz parte também da área de língua inglesa e suas literaturas. $O$ reconhecimento da área, no entanto, abre a possibilidade de que, no futuro, possam ser criadas vagas para a contratação de novos docentes efetivos especificamente na área de PLE.

A expansão do PLE/L2 na UFSCar é marcada também pela continuidade e ampliação das ações extensionistas na área: em consulta ao Portal da Transparência da ProEx/UFSCar, foram encontrados 81 projetos de extensão registrados no período de 2009 a 2021, vinculados ao DL, ao Departamento de Psicologia (DPsi), ao IL ou outras unidades acadêmicas, dos diferentes campi da universidade. Os projetos abarcam a oferta de cursos de PLE, atividades de recepção de estrangeiros, tandem, recepção e ensino de português para refugiados, ações no contexto do Programa Mais Médicos, eventos acadêmicos, aplicação do Celpe-Bras, ensino de português para surdos, 
formação de professores, ensino de português para indígenas, dentre outras ações ${ }^{21}$.

Esses dados sobre o PLE/L2 na UFSCar corroboram uma constatação de Furtoso (2015, p. 159) sobre a institucionalização da área em universidades brasileiras, em que "a extensão tem se configurado como a parte mais robusta do tripé", o que "revela uma área fortemente vinculada à prática". Para a autora, esse caráter fortemente extensionista da área não é um problema a priori, mas ela ressalta que é necessário haver um equilíbrio com as atividades de pesquisa e ensino, como forma de garantir "uma via de mão dupla entre teoria e prática" e o reconhecimento institucional da área.

Na UFSCar, a formação de professores de PLE/L2 se fortaleceu após 2010, quando passou a ser ofertada a estudantes dos cursos de Licenciatura em Letras a disciplina optativa (64335) "Ensino de Português para Estrangeiros: contextos e práticas", que tem por objetivo promover entre os estudantes "o desenvolvimento de capacitação para atuar no ensino de português para estrangeiros, a partir de conhecimento, discussão e reflexões envolvendo especificidades contextuais, materiais didáticos e componentes da prática pedagógica da área" (UFSCar ' [2021a]).

A disciplina, de 06 créditos (90h), é vinculada a projetos de extensão na área de PLE e possibilita aos discentes inscritos a familiarização com a área pelo cumprimento de aulas teóricas e de atividades práticas em aulas de PLE. Ao final da disciplina, as práticas dos estudantes são objeto de reflexão e discussão em um evento local, o "Colóquio Ação e Reflexão em Português para Estrangeiros", que em 2020 chegou a sua XI edição (COLÓQUIO , 2020).

$\mathrm{Na}$ reformulação curricular dos cursos de Licenciatura em Letras, ainda em discussão no Conselho de Curso e no Núcleo Docente Estruturante (NDE), prevê-se a inclusão de uma nova disciplina na área de PLE, de caráter obrigatório.

No curso de Bacharelado em Tradução e Interpretação em Língua Brasileira de Sinais/Língua Portuguesa (TILSP), criado em 2014 e alocado no DPsi, embora tenha por foco a formação de tradutores e intérpretes, é ofertada a disciplina obrigatória (1000668) "Português como segunda língua para surdos", que tem por objetivo levar os estudantes a "compreender os conceitos de primeira e de segunda língua e as práticas de ensino da língua portuguesa como segunda língua para surdos, além das teorias de linguagem

\footnotetext{
${ }^{21}$ Consulta e filtragem pelas palavras-chave "celpe-bras", "estrangeiro", "refugiado", "imigrante", "surdo" e "indígena". Os dados disponíveis na plataforma são apenas do ano de 2009 em diante (UFSCar, [2021a]).
} 
subjacentes" (UFSCar, [2021b]), sendo explicitada no seu Plano de Ensino a ênfase no ensino de PL2 na perspectiva discursivo-enunciativa da linguagem.

A partir dessas ações no âmbito do ensino na graduação, abre-se espaço para projetos maiores de formação de professores de PLE/L2 na instituição, fortalecendo a interrelação entre as ações de ensino, pesquisa e extensão.

\section{Pesquisa sobre PLE/L2 na UFSCar: levantamento de dados no RI}

No âmbito da pesquisa, pode-se dizer que, a partir das práticas extensionistas, o PLE/L2 tem sido objeto de investigação e publicações por docentes e discentes da UFSCar desde a década de 1990. No entanto, localizamos somente um levantamento sistemático de publicações na área que registra a produção científica da UFSCar que é a de Furtoso (2015). A autora mapeou trabalhos na área de PLE/L2 disponíveis no Catálogo de Dissertações e Teses da CAPES e identificou a UFSCar como uma das 32 instituições de ensino superior brasileiras que tinham, à época, pesquisas de mestrado e/ou doutorado na área, tendo sido mapeadas 04 dissertações defendidas no Programa de PósGraduação em Linguística da UFSCar (PPGL) entre 2006 e 2014.

Para este artigo, optou-se pelo levantamento de dados a partir das publicações disponíveis no RI da UFSCar, localizado na Biblioteca Comunitária (BCo) da universidade. O RI foi implementado em $2015^{22}$ com o objetivo de

[...] armazenar, preservar, organizar e disseminar amplamente a produção intelectual dos diversos setores e segmentos da comunidade da UFSCar, provendo o acesso aberto à informação produzida na instituição e registrada como científica, tecnológica, didática, artístico-cultural e técnico-administrativa (UFSCar, [2021c]).

A obrigatoriedade de entrega de teses e dissertações para disponibilização no RI foi instituída pela Resolução ConsUni no 835, de 4 de março de 2016, e a possibilidade de disponibilização de Trabalhos de Conclusão de Curso (TCC) se deu pela Resolução CoG no 322, de 27 de abril de 2020.

Na data de 05 de agosto de 2021, o acervo do RI totalizava 13.903 arquivos, sendo

\footnotetext{
22 Reconhece-se que essas publicações não refletem a totalidade da pesquisa da UFSCar, seja por não contemplarem outros gêneros de divulgação científica, como artigos, capítulos de livros, trabalhos em anais de congresso, participação em eventos, relatórios etc, dos discentes, docentes ou técnicos da instituição, seja pela eventual ausência de trabalhos de dissertação, tese ou, principalmente, TCC (ainda) não enviados para hospedagem no repositório. Em consulta à agenda de defesas do PPGL, por exemplo, encontrou-se a informação de que foram defendidos, entre maio e julho de 2021, pelo menos três trabalhos na área, ainda não enviados para o RI: a dissertação de Camila Ribeiro Corrêa de Moraes, e as teses de Tábata Quintana Yonaha e Jorcemara Matos Cardoso.
} 
9.077 dissertações, 4.142 teses e 667 TCCs $^{23}$. Por serem esses os gêneros de divulgação científica que materializam as investigações empreendidas como requisito para conclusão dos cursos de graduação, mestrado e doutorado, assume-se que os dados disponíveis no RI constituem um corpus importante e representativo para se identificar os objetos de pesquisa que têm feito parte da agenda de investigação da comunidade universitária.

O levantamento de dados para este estudo foi realizado entre os dias 10 e 15 de julho de 2021, por dois procedimentos complementares. Em um primeiro momento, foi utilizada a ferramenta de buscas do próprio RI utilizando as palavras-chave: "Português língua estrangeira" (que gerou 41 resultados), "Português língua adicional" (1 resultado), "Português para estrangeiros" (31 resultados), "Português língua de acolhimento" (1 resultado), "Português língua de herança" (1 resultado), "Português língua não materna" (3 resultados), "Português para falantes de outras línguas" (18 resultados), "Português como segunda língua" (1 resultado), "Português para surdos" (6 resultados) e "Português para indígenas" (nenhum resultado). Ao final dessa busca, constituiu-se uma lista de 107 resultados, mas em que constavam algumas duplicações, referentes a trabalhos identificados pelo uso de mais de uma das palavras-chave pesquisadas, e também trabalhos que não eram propriamente da área mas que faziam menção a estudos ou publicações sobre o PLE/L2 ao longo do texto e, por isso, foram identificados pelo buscador.

Em um segundo momento de levantamento de dados, procedeu-se a uma análise individual de todos os trabalhos indexados em pelo menos uma das subáreas da grande área de Letras, Linguística e Artes. Eram, ao todo, 32 subáreas, que somavam 749 resultados, entre os quais encontraram-se também duplicações, devido a trabalhos associados a duas ou mais subáreas. A seleção preliminar de trabalhos nesta etapa se baseou em uma análise, em sequência, conforme necessidade, do título, do resumo e das palavras-chave do texto, para identificar aqueles que, potencialmente, tratariam de questões relativas à área de PLE/L2. Assim, foram destacados 66 trabalhos, que se somaram à lista de resultados pelas palavras-chave.

A adoção de dois procedimentos para levantamento de dados justifica-se por um

\footnotetext{
${ }^{23}$ Reconhece-se que há limitações no acervo, em razão da disponibilização de TCCs somente a partir da Resolução CoG no 311/2020. Dos cursos de Licenciatura em Letras, por exemplo, no dia 05 de agosto de 2021 eram apenas 29 os TCCs disponíveis no RI: 25 de Letras - Espanhol e 04 de Letras - Inglês, número pouco representativo da totalidade de investigações de TCC realizadas nos 25 anos de existência do curso. Os relatórios de Iniciação Científica e Tecnológica não são publicizados pela instituição.
} 
esforço de se constituir um corpus mais completo, suprindo falhas nos mecanismos de um dos métodos de busca com os resultados do outro.

Posteriormente, os 173 resultados das buscas foram reunidos, eliminaram-se as duplicações e procedeu-se a uma seleção daqueles que efetivamente investigavam questões relativas ao $P L E / L 2$, a partir de uma leitura atenta do resumo dos trabalhos e, quando necessário, de partes da introdução e do capítulo de metodologia. O critério adotado para a seleção foi de que o objetivo do trabalho estivesse relacionado a questões de ensino, aprendizagem, uso, avaliação ou de políticas linguísticas relativas ao português em contextos em que o idioma não é a língua de socialização inicial. Nesse sentido foram descartados trabalhos que tratavam, por exemplo, da aprendizagem colaborativa de línguas pelo programa Tandem (contexto que envolvia sujeitos estrangeiros aprendentes de português), mas cujo objetivo era relacionado à experiência de aprendizagem de inglês, espanhol ou outra língua por brasileiros, não o PLE/L2. De outro lado, foram incluídos trabalhos que, sem explicitar uma vinculação à área de PLE/L2, ou mesmo à Linguística Aplicada, se propunham a investigar aspectos linguísticos de variedades do português falado como LE ou como L2.

\section{Organização e categorização dos dados}

Os trabalhos selecionados foram classificados com base nos seguintes critérios: autoria, orientação, tipo de texto (TCC, dissertação ou tese), ano de publicação, curso de graduação ou programa de pós-graduação em que foi desenvolvido, linha de pesquisa (quando pertinente) e tema da investigação.

Para a classificação dos temas, partiu-se das categorias estabelecidas por Furtoso (2015) em seu mapeamento, mas foram feitas algumas alterações para melhor representar as especificidades do corpus. As categorias adotadas foram: material didático, descrição/análise linguística, aspectos da (sala de) aula, formação/atuação de professores, Celpe-Bras e outras práticas avaliativas, políticas linguísticas, e questões da subjetividade do aprendente/falante. A categorização dos temas, evidentemente, é produto de um gesto interpretativo do pesquisador, embora sejam adotados critérios e referências com vistas a uma classificação mais objetiva. Em alguns casos, os trabalhos poderiam associar-se a mais de uma das categorias de temas, por terem um escopo mais amplo ou por se construírem na interface de duas ou mais das categorias destacadas. 
Nesses casos, optou-se pela classificação com base no tema que se interpretou como mais sobressalente conforme os objetivos e resultados do trabalho.

Na próxima seção, apresentaremos os resultados e discussões sobre as pesquisas disponíveis no RI da UFSCar.

\section{As pesquisas em PLE/L2 no RI/UFSCar}

Foram mapeados, ao todo, 40 trabalhos na área de PLE/L2 no RI/UFSCar: 9 TCCs (8 de graduandos em Letras-Espanhol e 1 em TILSP), 19 dissertações (1 de mestrado em Educação Especial e 18 em Linguística) e 12 teses (3 de doutorado em Educação Especial e 9 em Linguística). A lista completa de trabalhos pode ser consultada a seguir.

Quadro 1 - Mapeamento de publicações em PLE/L2 no RI/UFSCar

\begin{tabular}{|c|c|c|c|}
\hline AUTORIA & ORIENTAÇÃO & TEXTO & TRABALHO \\
\hline $\begin{array}{l}\text { Ricardo Moutinho } \\
\text { Rodrigues da Silva } \\
\qquad(2006)\end{array}$ & Nelson Viana & $\begin{array}{l}\text { Dissertação } \\
\text { (PPGL) }\end{array}$ & $\begin{array}{l}\text { O efeito retroativo do Celpe-Bras na cultura de aprender } \\
\text { de candidatos ao exame }\end{array}$ \\
\hline $\begin{array}{l}\text { Aline Fraiha Paiva } \\
\text { (2009) }\end{array}$ & Nelson Viana & $\begin{array}{l}\text { Dissertação } \\
\text { (PPGL) }\end{array}$ & $\begin{array}{l}\text { Perspectivas (inter)culturais em séries didáticas de } \\
\text { português língua estrangeira }\end{array}$ \\
\hline $\begin{array}{l}\text { Valdete de Lima Ank } \\
\text { Morais (2009) }\end{array}$ & Nelson Viana & $\begin{array}{l}\text { Dissertação } \\
\text { (PPGL) }\end{array}$ & $\begin{array}{l}\text { As não-coincidências interlocutivas do dizer de sujeitos } \\
\text { hispanos-falantes em discursividades brasileiras: seus } \\
\text { reflexos em formulações imaginárias }\end{array}$ \\
\hline $\begin{array}{l}\text { Laís Santos da Silva } \\
\qquad(2010)\end{array}$ & Rosa Yokota & $\begin{array}{l}\text { TCC (Letras } \\
\text { - Espanhol) }\end{array}$ & $\begin{array}{l}\text { As formas de preenchimento do objeto direto na } \\
\text { aprendizagem de português/LE por argentinos }\end{array}$ \\
\hline Talita Barizon (2010) & $\begin{array}{l}\text { Lucia Maria de } \\
\text { Assunção } \\
\text { Barbosa }\end{array}$ & $\begin{array}{l}\text { Dissertação } \\
\text { (PPGL) }\end{array}$ & $\begin{array}{l}\text { Faces do Brasil e dos brasileiros em imagens de livros } \\
\text { didáticos de portuquês para estrangeiros }\end{array}$ \\
\hline $\begin{array}{l}\text { Luiz Henrique Siloto } \\
\qquad(2011)\end{array}$ & $\begin{array}{l}\text { Sandra Regina } \\
\text { Buttros Gattolin }\end{array}$ & $\begin{array}{l}\text { Dissertação } \\
\text { (PPGL) }\end{array}$ & $\begin{array}{l}\text { O ensino comunicativo de português língua estrangeira } \\
\text { em contexto especifico: uma reflexão sobre a sala de } \\
\text { aula }\end{array}$ \\
\hline $\begin{array}{l}\text { Renata Alves de } \\
\text { Oliveira (2011) }\end{array}$ & $\begin{array}{l}\text { Sandra Regina } \\
\text { Buttros Gattolin }\end{array}$ & $\begin{array}{l}\text { Dissertação } \\
\text { (PPGL) }\end{array}$ & $\begin{array}{l}\text { Programa Escolas Bilingues de Fronteira: das } \\
\text { generalizações do documento às especificidades da } \\
\text { fronteira entre Foz do Iguaçu e Puerto Iguazu }\end{array}$ \\
\hline $\begin{array}{l}\text { Fernanda Tonello } \\
\text { (2012) }\end{array}$ & $\begin{array}{l}\text { Lucia Maria de } \\
\text { Assunção } \\
\text { Barbosa }\end{array}$ & $\begin{array}{l}\text { Dissertação } \\
\text { (PPGL) }\end{array}$ & $\begin{array}{l}\text { O gênero musical samba como conteúdo cultural no } \\
\text { ensino de PLE: uma experiência com aprendentes } \\
\text { hispanofalantes }\end{array}$ \\
\hline $\begin{array}{l}\text { Telma Gomes Novato } \\
\text { Sant'Anna (2012) }\end{array}$ & $\begin{array}{l}\text { Maria Isabel de } \\
\text { Moura }\end{array}$ & $\begin{array}{l}\text { Dissertação } \\
\text { (PPGL) }\end{array}$ & $\begin{array}{l}\text { Escrevo numa língua que não é minha.: apontamentos } \\
\text { sobre processo de ensino e aprendizagem da língua } \\
\text { portuquesa escrita por surdos alfabetizados }\end{array}$ \\
\hline $\begin{array}{l}\text { Julio Orlando Gallardo } \\
\qquad(2012)\end{array}$ & Nelson Viana & $\begin{array}{l}\text { Dissertação } \\
\text { (PPGL) }\end{array}$ & $\begin{array}{l}\text { Representações de professores em formação em } \\
\text { relação à internet no ensino de português para } \\
\text { estrangeiros em contexto de imersão }\end{array}$ \\
\hline
\end{tabular}


GRANATO, M.; YOKOTA, R.

\begin{tabular}{|c|c|c|c|}
\hline $\begin{array}{l}\text { Marina Ayumi Izaki } \\
\quad \text { (2013) }\end{array}$ & Nelson Viana & $\begin{array}{l}\text { Dissertação } \\
\quad \text { (PPGL) }\end{array}$ & $\begin{array}{l}\text { Professores em formação: significados construídos no } \\
\text { processo de interaçãa em sala de aula de português } \\
\text { língua estrangeira }\end{array}$ \\
\hline $\begin{array}{l}\text { Natália Santini Victuri } \\
\text { (2013) }\end{array}$ & $\begin{array}{l}\text { Antón Castro } \\
\text { Míguez }\end{array}$ & $\begin{array}{l}\text { TCC (Letras } \\
\text { - Espanhol) }\end{array}$ & $\begin{array}{l}\text { Materialidades da legislação linguística do Brasil e da } \\
\text { Argentina no contexto do Mercosul }\end{array}$ \\
\hline $\begin{array}{l}\text { Eleonora Bambozzi } \\
\text { Bottura (2014) }\end{array}$ & $\begin{array}{l}\text { Sandra Regina } \\
\text { Buttros Gattolin }\end{array}$ & $\begin{array}{l}\text { Dissertação } \\
\text { (PPGL) }\end{array}$ & $\begin{array}{l}\text { Exame Celpe-Bras: uma investigação sobre o papel do } \\
\text { entrevistador na interação face a face }\end{array}$ \\
\hline $\begin{array}{l}\text { Marcia Fanti Negri } \\
\text { (2014) }\end{array}$ & Nelson Viana & $\begin{array}{l}\text { Dissertação } \\
\quad \text { (PPGL) }\end{array}$ & $\begin{array}{l}\text { Competências do } \text { professor de } \text { Português Línqua } \\
\text { Estrangeira (PLE) } \\
\text { reflexão }\end{array}$ \\
\hline $\begin{array}{c}\text { Aline Raquel } \\
\text { Franceschini (2014) }\end{array}$ & $\begin{array}{l}\text { Rita de Cássia } \\
\text { Barbirato } \\
\text { Thomaz de } \\
\text { Moraes }\end{array}$ & $\begin{array}{l}\text { Dissertação } \\
\quad \text { (PPGL) }\end{array}$ & $\begin{array}{l}\text { A relação da competência comunicativa com o } \\
\text { planejamento temático baseado em tarefas em um } \\
\text { curso de português língua estrangeira }\end{array}$ \\
\hline $\begin{array}{l}\text { Ana Luiza Suficiel } \\
\qquad(2014)\end{array}$ & $\begin{array}{l}\text { Antón Castro } \\
\text { Míguez }\end{array}$ & - Espa & $\begin{array}{l}\text { Atitudes ante as práticas linquísticas na fronteira entre } \\
\text { Argentina e Brasil: o portunhol de Misiones }\end{array}$ \\
\hline $\begin{array}{c}\text { Glaucia Regina Gomes } \\
\text { (2014) }\end{array}$ & $\begin{array}{l}\text { Maria Silva } \\
\text { Cintra Martins }\end{array}$ & Tese (PPGL) & $\begin{array}{l}\text { Escrita acadêmica e identidade: } 0 \text { processo de } \\
\text { apropriação de gêneros acadêmicos por graduandos } \\
\text { indígenas }\end{array}$ \\
\hline $\begin{array}{l}\text { Alice Almeida Chaves } \\
\text { de Resende (2015) }\end{array}$ & $\begin{array}{l}\text { Cristina Broglia } \\
\text { Feitosa de } \\
\text { Lacerda }\end{array}$ & $\begin{array}{c}\text { Tese } \\
\text { (PPGEEs) }\end{array}$ & $\begin{array}{l}\text { Avaliação pedagógica para alunos surdos no contexto } \\
\text { de um programa inclusivo bilínque }\end{array}$ \\
\hline $\begin{array}{l}\text { Sara Regir } \\
\text { Braga ( }\end{array}$ & Rosa Yokota & s & O convívio de línguas en Ciudad del Este-Paraguai \\
\hline $\begin{array}{l}\text { Mirelle Amaral de São } \\
\text { Bernardo (2016) }\end{array}$ & $\begin{array}{l}\text { Lucia Maria de } \\
\text { Assunção } \\
\text { Barbosa }\end{array}$ & Tese (PPGL) & $\begin{array}{l}\text { Português como Língua de Acolhimento: um estudo com } \\
\text { imigrantes e pessoas em situação de refúgio no Brasil }\end{array}$ \\
\hline $\begin{array}{l}\text { Djair Lázaro de } \\
\text { Almeida (2016) }\end{array}$ & $\begin{array}{l}\text { Cristina Broglia } \\
\text { Feitosa de } \\
\text { Lacerda }\end{array}$ & $\begin{array}{c}\text { Tese } \\
\text { (PPGEEs) }\end{array}$ & $\begin{array}{l}\text { Português como segunda língua para surdos: a escrita } \\
\text { construída em situaçõ̃es de interação mediadas pela } \\
\text { Libras }\end{array}$ \\
\hline $\begin{array}{l}\text { Caroline Veloso da } \\
\quad \text { Silva (2016) }\end{array}$ & Nelson Viana & Tese (PPGL) & $\begin{array}{l}\text { Representações sociais de aprendizes de português em } \\
\text { contexto sul-africano sobre a língua e a cultura do } \\
\text { Brasil: subsídios para políticas de difusão e reflexões } \\
\text { sobre o ensino de português no exterior }\end{array}$ \\
\hline $\begin{array}{l}\text { Elaine Risques Faria } \\
\qquad(2017)\end{array}$ & $\begin{array}{l}\text { Sandra Regina } \\
\text { Buttros Gattolin } \\
\text { de Paula }\end{array}$ & Tese (PPGL) & $\begin{array}{l}\text { Avaliação de proficiência oral em língua estrangeira: } \\
\text { foco nos elementos provocadores na interação face a } \\
\text { face do exame Celpe-Bras }\end{array}$ \\
\hline $\begin{array}{l}\text { Camila Leitão Previato } \\
\text { (2017) }\end{array}$ & $\begin{array}{l}\text { Antón Castro } \\
\text { Míguez }\end{array}$ & $\begin{array}{l}\text { TCC (Letras } \\
\text { - Espanhol) }\end{array}$ & $\begin{array}{l}\text { Análise de alguns aspectos do processo de aquisição da } \\
\text { língua portuguesa por estudantes hispano-americanos } \\
\text { na Universidade Federal de São Carlos em contextos de } \\
\text { instrução formal e imersão }\end{array}$ \\
\hline $\begin{array}{l}\text { Beatriz Damaciano } \\
\text { Paulo Chalucuane } \\
\quad \text { (2017) }\end{array}$ & $\begin{array}{l}\text { Renato Miguel } \\
\text { Basso }\end{array}$ & $\begin{array}{l}\text { Dissertação } \\
\quad \text { (PPGL) }\end{array}$ & $\begin{array}{l}\text { As influências das línguas bantu no português falado em } \\
\text { Moçambique: um estudo descritivo do Cindau }\end{array}$ \\
\hline $\begin{array}{l}\text { Diléia Aparecida } \\
\text { Martins Briega (2017) }\end{array}$ & $\begin{array}{l}\text { Cristina Broglia } \\
\text { Feitosa de } \\
\text { Lacerda }\end{array}$ & $\begin{array}{c}\text { Tese } \\
\text { (PPGEEs) }\end{array}$ & $\begin{array}{l}\text { O ENEM como via de acesso do surdo ao ensino superior } \\
\text { brasileiro }\end{array}$ \\
\hline $\begin{array}{l}\text { Marina Ayumi Izaki } \\
\text { Gómez (2018) }\end{array}$ & Nelson Viana & Tese (PPGL) & $\begin{array}{l}\text { Saberes docentes e desafios no ensino de Português } \\
\text { língua estrangeira na atuação de professores em } \\
\text { formação }\end{array}$ \\
\hline $\begin{array}{l}\text { Mariana Teixeira da } \\
\text { Hora (2018) }\end{array}$ & Camila Höfling & $\begin{array}{l}\text { TCC (Letras } \\
\text { - Espanhol) }\end{array}$ & "Servirão lasanha no RU amanhã": alguém fala assim? \\
\hline
\end{tabular}


Português como LE/L2 na UFSCar: mapeando os registros sobre extensão, ensino e pesquisa

\begin{tabular}{|c|c|c|c|}
\hline $\begin{array}{l}\text { Giovana Nicolini Milozo } \\
\text { (2019) }\end{array}$ & $\begin{array}{l}\text { Sandra Regina } \\
\text { Buttros Gattolin } \\
\text { de Paula }\end{array}$ & $\begin{array}{l}\text { Dissertação } \\
\quad \text { (PPGL) }\end{array}$ & $\begin{array}{l}\text { Práticas translíngues na comunicação de aprendizes de } \\
\text { português como língua estrangeira }\end{array}$ \\
\hline $\begin{array}{l}\text { Bruno Henrique da } \\
\quad \text { Silva (2019) }\end{array}$ & Janaina Cabello & TCC (TILSP) & $\begin{array}{l}\text { Educação de surdos indígenas em uma comunidade } \\
\text { Pankararu no interior de Pernambuco: educação } \\
\text { bilíngue, educação inclusiva ou o quê? }\end{array}$ \\
\hline $\begin{array}{l}\text { Marcia Fanti Negri } \\
\text { (2019) }\end{array}$ & Nelson Viana & Tese (PPGL) & $\begin{array}{l}\text { Representações sociais e interculturalidade: um estudo } \\
\text { documental sobre elementos provocadores e roteiros de } \\
\text { interação do exame Celpe-Bras }\end{array}$ \\
\hline $\begin{array}{l}\text { Jéssica Rodrigues Rosa } \\
\text { (2019) }\end{array}$ & Rosa Yokota & $\begin{array}{l}\text { Dissertação } \\
\text { (PPGL) }\end{array}$ & $\begin{array}{l}\text { Espanhol e português: os pronomes pessoais sujeito em } \\
\text { produções escritas em língua não materna }\end{array}$ \\
\hline $\begin{array}{l}\text { Eleonora Bambozzi } \\
\text { Bottura (2019) }\end{array}$ & $\begin{array}{l}\text { Sandra Regina } \\
\text { Buttros Gattolin }\end{array}$ & Tese (PPGL) & $\begin{array}{l}\text { "Como é no seu país?" Estudo autoetnográfico de uma } \\
\text { prática pedagógica em Português Língua de } \\
\text { Acolhimento para mulheres migrantes no Brasil: } \\
\text { implicações para a formação de professores }\end{array}$ \\
\hline Helena Boschi (2019) & $\begin{array}{l}\text { Luciana Salazar } \\
\text { Salgado }\end{array}$ & Tese (PPGL) & $\begin{array}{l}\text { Língua, cultura e comunidades discursivas: um estudo } \\
\text { sobre materiais didáticos de Português Língua } \\
\text { Estrangeira (PLE) }\end{array}$ \\
\hline $\begin{array}{l}\text { Amanda Castilho Azzali } \\
\text { (2019) }\end{array}$ & $\begin{array}{l}\text { Carolina de } \\
\text { Paula Machado }\end{array}$ & $\begin{array}{l}\text { Dissertação } \\
\text { (PPGL) }\end{array}$ & $\begin{array}{l}\text { A designação das línguas e sua distribuição para } \\
\text { falantes na tríplice fronteira Brasil - Paraguai - Argentina }\end{array}$ \\
\hline $\begin{array}{l}\text { Lucas Antonio Ribeiro } \\
\text { (2019) }\end{array}$ & $\begin{array}{l}\text { Antón Castro } \\
\text { Míguez }\end{array}$ & $\begin{array}{l}\text { TCC (Letras } \\
\text { - Espanhol) }\end{array}$ & $\begin{array}{l}\text { A educação dos surdos no Brasil: pesquisa histórica e } \\
\text { constatações em um contexto específico }\end{array}$ \\
\hline Márcia Cruz (2019) & $\begin{array}{l}\text { Lara Ferreira dos } \\
\text { Santos }\end{array}$ & $\begin{array}{l}\text { Dissertação } \\
\text { (PPGEEs) }\end{array}$ & $\begin{array}{l}\text { Orientações curriculares para o ensino de português } \\
\text { para surdos: análise de documento do município de São } \\
\text { Paulo }\end{array}$ \\
\hline $\begin{array}{l}\text { Fidel Armando Cañas } \\
\text { Chávez (2019) }\end{array}$ & $\begin{array}{l}\text { Lucia Maria de } \\
\text { Assunção } \\
\text { Barbosa }\end{array}$ & Tese (PPGL) & $\begin{array}{l}\text { "Aqui não é um paraíso, mas é muito bom": imersão e } \\
\text { identidade de jovens africanos francófonos aprendizes } \\
\text { de português no Distrito Federal }\end{array}$ \\
\hline $\begin{array}{l}\text { Joyce Cristina Souza } \\
\text { (2020) }\end{array}$ & $\begin{array}{l}\text { Gladis M de B. } \\
\text { Almeida }\end{array}$ & $\begin{array}{l}\text { Dissertação } \\
\text { (PPGL) }\end{array}$ & $\begin{array}{l}\text { Dicionários bilíngues português-Libras no ensino para } \\
\text { surdos: usos e funções }\end{array}$ \\
\hline $\begin{array}{l}\text { Matheus Granato } \\
\qquad(2021)\end{array}$ & Rosa Yokota & $\begin{array}{l}\text { TCC (Letras } \\
\text { - Espanhol) }\end{array}$ & $\begin{array}{l}\text { Ela faz a interlíngua dela: estudo exploratório sobre a } \\
\text { aprendizagem dos possessivos de terceira pessoa do } \\
\text { português brasileiro por falantes de espanhol }\end{array}$ \\
\hline
\end{tabular}

Fonte: Elaborado pelos autores.

No PPGL, encontram-se trabalhos nas três linhas de pesquisa do programa: Linguagem e Discurso (2 trabalhos), Descrição, linguagem humana e tecnologia (2 trabalhos) e Ensino e aprendizagem de línguas (23 trabalhos). No Programa de PósGraduação em Educação Especial (PPGEEs), os 4 trabalhos mapeados foram desenvolvidos na linha de pesquisa em Produção científica e formação de recursos humanos em Educação Especial.

Interessa notar que, embora a área de PLE/L2 esteja presente nos quatro campi da UFSCar por meio de atividades extensionistas, os trabalhos de pesquisa mapeados são todos do campus de São Carlos, o que se justifica pela maior institucionalização dos 
estudos da linguagem e da formação de professores de PLE/L2 neste campus²4.

Em perspectiva temporal, observamos uma distribuição variável na quantidade de trabalhos defendidos por ano, como representado no Gráfico 1.

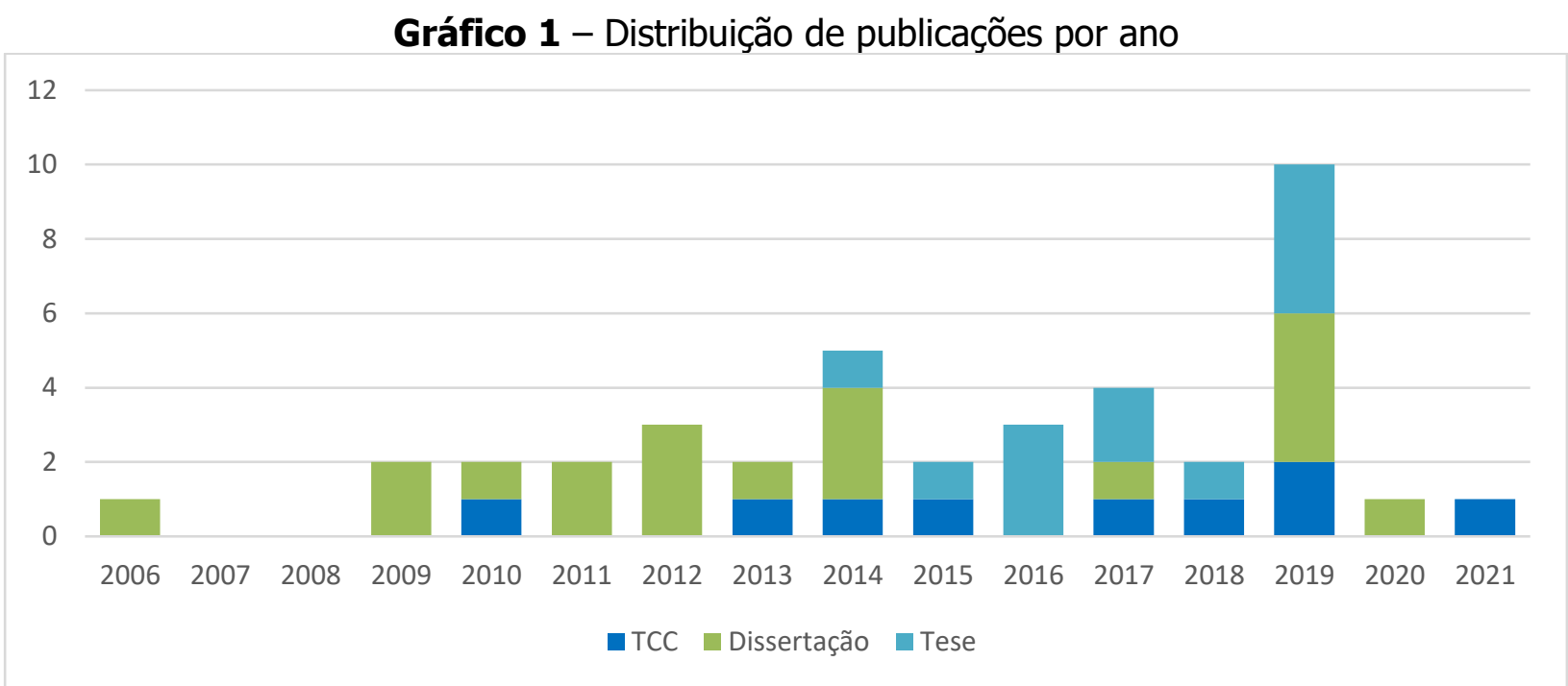

Fonte: Elaborado pelos autores.

No que se refere aos TCCs, os trabalhos mapeados são do ano de 2010 em diante, o que coincide com o período de oferta da disciplina optativa de formação de professores de PLE/L2 a estudantes do curso de Letras. No entanto, a baixa disponibilidade de TCCs no RI, especialmente os anteriores à criação do RI, dificulta a formulação de conclusões mais definitivas a respeito. Quanto às dissertações e teses, os 4 trabalhos mapeados do PPGEEs, todos eles enfocando a educação de surdos, são posteriores a 2014, ano de criação do TILSP, o que pode refletir um contexto particularmente propício para as investigações na área, ao mesmo tempo motivadas pela e motivadoras da institucionalização dos estudos sobre a educação de surdos e a interface libras/português na UFSCar, movimento que deve se intensificar nos próximos anos.

No caso do PPGL, nota-se que a pesquisa em PLE/L2 está presente desde a criação do programa, sendo que a primeira dissertação foi defendida no ano de 2006 e a primeira tese, em 2014, períodos em que os primeiros estudantes dos cursos de mestrado (criado em 2005) e de doutorado (criado em 2010) concluíram seus trabalhos ${ }^{25}$. As publicações

\footnotetext{
${ }^{24}$ Para um aprofundamento deste estudo, caberia investigar de que modo o conhecimento produzido na área pelas atividades empreendidas nos demais campitem circulado como produção acadêmica. A título de exemplo, destacamos o trabalho de Caron; Bracciali (2010) sobre as atividades no campus de Sorocaba,

${ }^{25}$ Efetivamente, a primeira dissertação de mestrado defendida no programa foi na área de PLE, em 2006.
} 
da área têm sido constantes no PPGL desde então, com pico no ano de 2019, quando foram defendidas 4 teses e 3 dissertações.

Quanto aos temas, observou-se uma distribuição relativamente equilibrada entre as diferentes categorias observadas, como ilustrado no Gráfico 2.

Gráfico 2 - Temas investigados

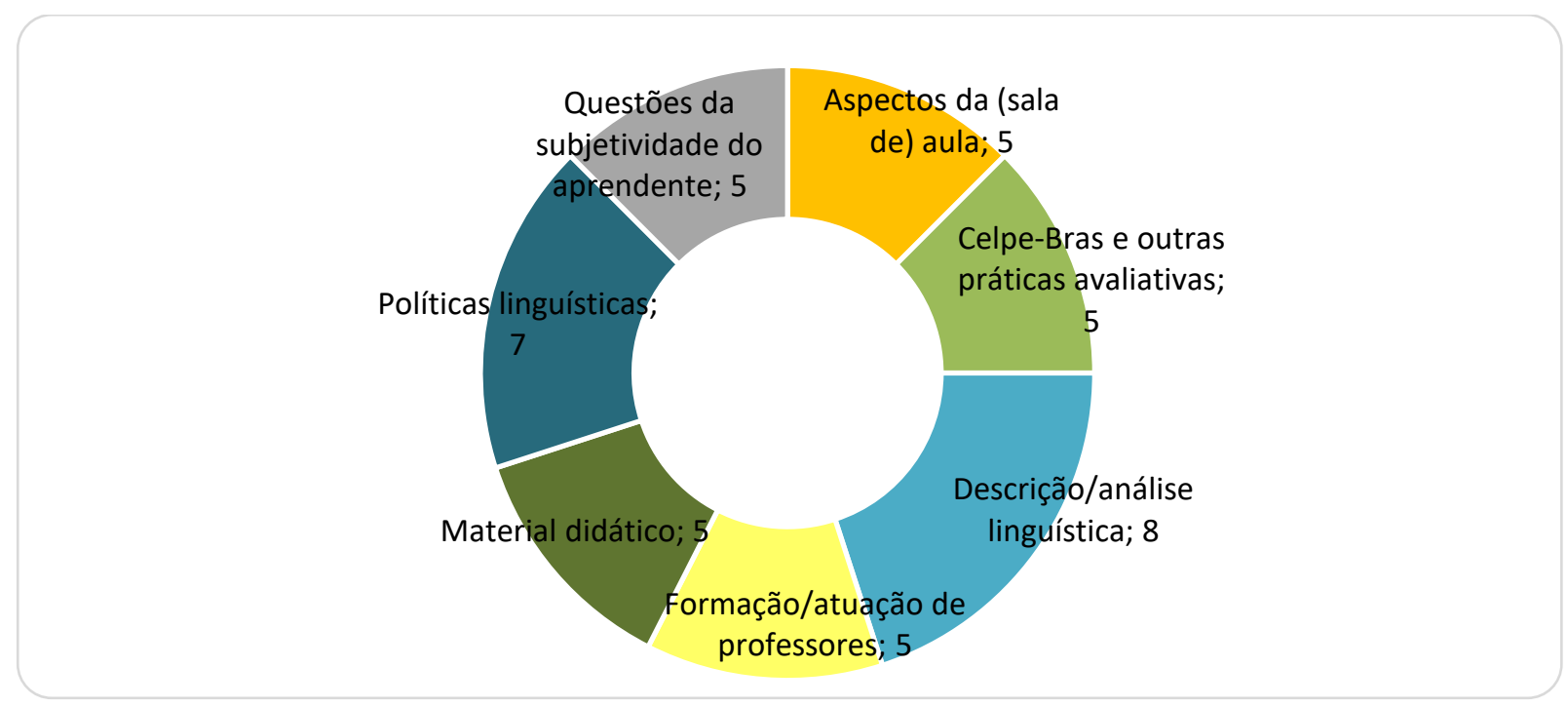

Fonte: Elaborado pelos autores.

Como se observa, nas sete categorias estabelecidas houve ocorrência de 5 a 8 trabalhos. Entre as mais investigadas, estão a descrição/análise linguística e as políticas linguísticas. No primeiro caso, encontram-se trabalhos que têm por corpus de análise a produção em português como LE/L2 pelos sujeitos investigados, com foco em questões estruturais ou discursivas, normalmente analisadas a partir do diálogo com outras áreas de investigação, como a sociolinguística de contato, as teorias de aquisição e aprendizagem de línguas ou teorias sociointeracionais. Desse grupo, destacam-se particularmente as pesquisas que abordam a interface português/espanhol. Já na categoria das políticas linguísticas, encontram-se trabalhos com foco em questões educacionais e governamentais sobre o ensino, a valorização e a circulação de línguas em contextos específicos, trabalhos nem sempre vinculados à Política Linguística enquanto área de investigação. Destacam-se os estudos com foco na circulação de línguas em contextos de fronteira ou do Mercosul e os estudos com ênfase no sujeito surdo e seu acesso à educação.

Dos trabalhos sobre práticas avaliativas, predominam aqueles com foco no exame 
Celpe-Bras, que foi analisado em diferentes aspectos. Dos cinco estudos mapeados nessa categoria, apenas um não trata do exame: uma tese defendida no PPGEEs que aborda o conceito de avaliação pedagógica no contexto da educação de surdos. Entre os trabalhos com materiais didáticos, todos tratam do contexto de PLE, e as questões relativas à interculturalidade e à representação cultural brasileira são as que se sobressaem.

Nas demais categorias, tem-se uma maior diversidade de estudos no que se refere às teorias, objetivos e públicos enfocados. Em "Aspectos da (sala de) aula", estão reunidos estudos que tratam de experiências e práticas pedagógicas, bem como estudos de cunho etnográfico sobre contextos específicos de ensino e aprendizagem. Em "Formação/atuação de professores", estão estudos cujo foco é a formação docente e que se articulam a partir de estudos autoetnográficos, interacionais, na linha dos estudos sobre competências do professor ou dos saberes docentes. Em "Questões da subjetividade do aprendente/falante", encontram-se trabalhos que, por diferentes perspectivas teóricas, discutem crenças, atitudes linguísticas, representações e/ou imaginários do aprendente/falante e seu reflexo no uso e na circulação do PLE/L2, por vezes em contato com outras línguas.

A diversidade de temas representados corresponde à tendência observada por Furtoso (2015) de aumento nas pesquisas em temas emergentes (como formação de professores, Celpe-Bras e políticas linguísticas) nos últimos anos.

Essa diversidade se reflete também nas palavras-chave dos 40 trabalhos identificados no RI. São 116 palavras-chave diferentes, sendo as mais recorrentes: Educação de surdos (3 ocorrências), Formação de professores (3), Material didático (3), Bilinguismo (4), Celpe-Bras (4), Interação (4), Português para estrangeiros (4), Representações (4), Surdez (4), Ensino e aprendizagem de línguas (5) e Português como Língua Estrangeira (11).

Assim como nos dados de Furtoso (2015), a maior parte dos estudos mapeados no RI têm por foco os aprendentes estrangeiros (55\% do total). Entre os demais trabalhos, destacam-se aqueles que têm por foco comunidades surdas ( $20 \%$ do total) e aqueles que investigam os contextos de fronteira e do Mercosul ( $15 \%$ do total). 0 contexto de imigrantes de crise e refugiados foi objeto de discussão em duas teses do PPGL. No caso das comunidades indígenas, identificaram-se apenas uma tese, com foco em práticas de letramento acadêmico de universitários indígenas, e um TCC, que avaliou a educação de surdos indígenas em uma escola do estado de Pernambuco. $O$ contexto 
dos demais países de língua oficial portuguesa foi pouco explorado, havendo uma única dissertação que investiga a influência de línguas bantu no português falado em Moçambique.

Não foram objeto de discussão nas pesquisas mapeadas no presente estudo os contextos de comunidades históricas e do português como língua de herança, destacados por Bulla; Kuhn (2020) e Rocha (2019) como perfis implicados na área de PLE/L2.

\section{Considerações finais}

Este estudo teve por propósito contribuir com a compreensão do processo de institucionalização da área de PLE/L2 na UFSCar. O texto se construiu a partir de dois movimentos centrais: primeiramente, foi apresentado um histórico de ações na área de PLE/L2 implementadas na UFSCar. Num segundo momento, a partir de um mapeamento e análise das publicações da área disponíveis no RI, foi nosso objetivo avaliar a presença de TCCs, dissertações e teses na área defendidos na instituição e os temas e contextos que têm sido mais explorados.

Num quadro geral, observa-se que a institucionalização do PLE/L2 na UFSCar seguiu percurso similar ao de outras instituições de ensino superior brasileiras (FURTOSO, 2015; SCAMARAMUCCI; BIZON, 2020; BRASIL, 2021). As primeiras ações se deram no âmbito da extensão universitária, ainda na década de 1990, a partir da atuação de docentes do DL em resposta a uma demanda institucional de formação linguística em língua portuguesa de estudantes do PEC-G (BARBOSA, 1996). O caráter prático da área tem se mantido forte na instituição, mais de 25 anos depois, pelas constantes ações extensionistas. Particularmente a partir dos últimos quinze anos, as ações de ensino e pesquisa na área têm traçado caminhos mais robustos na instituição, marcados pela oferta de disciplinas para a formação de graduandos em Letras e TILSP.

No que se refere às atividades de pesquisa contempladas no mapeamento deste estudo, verificou-se que o PLE/L2 tem sido objeto de investigação e discussão na UFSCar desde a criação do PPGL, em 2005. Particularmente na última década, observa-se um significativo aumento na quantidade de tais pesquisas, na forma de TCCs de graduandos em Letras - Espanhol e em TILSP, e de dissertações e teses do PPGL e do PPGEEs, todos do campus São Carlos da UFSCar.

Os dados coletados, como se quis enfatizar, não representam a totalidade da pesquisa e divulgação científica na área de PLE/L2 da instituição, mas um recorte a partir 
dos trabalhos disponíveis no RI. Entre os trabalhos mapeados, observou-se um predomínio dos estudos com foco em aprendentes estrangeiros (pouco mais da metade do total), destacando-se também os trabalhos sobre aprendentes surdos, a partir de trabalhos não só do TILSP e do PPGEEs, mas também do PPGL e da licenciatura em Letras. Os temas se mostraram bastante diversos, corroborando uma tendência contemporânea da área (FURTOSO, 2015). Os temas que foram observados como mais recorrentes envolvem práticas de análise/descrição linguística e questões de políticas linguísticas, muitas vezes abordadas em interface com outros campos de estudo.

\section{Referências}

ALMEIDA FILHO, José Carlos Paes de; LOMBELLO, Leonor Cantareiro (org.). O ensino do Português para estrangeiros: pressupostos para o planejamento de cursos e elaboração de materiais. Campinas, Pontes, 1989.

ASOCIACIÓN DE UNIVERSIDADES GRUPO MONTEVIDEO. Núcleo Disciplinário. ND enseñanza de español y portugués como L2/LE. [S. I.: s. n.], [2021]. Disponível em: http://grupomontevideo.org/ndca/ndpelse/?page_id=18. Acesso em jul. de 2021.

BALEEIRO, Marisa; EL-DASH, Linda; LOMBELLO, Leonor Cantareiro. Subsídios para a elaboração de material didático para falantes de espanhol. Trabalhos em Lingüística Aplicada, Campinas, v. 1, p. 117-128, 1983. Disponível em: https://periodicos.sbu.unicamp .br/ojs/index.php/tla/article/view/8638946. Acesso em: 25 set. 2021.

BARBOSA, Lúcia Maria de Assunção. Relato de uma experiência com o ensino de português para estrangeiros. Estudos Linguísticos, São Paulo, v. 25, p. 279-281, 1996. Disponível em:

http://www.gel.hospedagemdesites.ws/arquivo/anais/1308581051_47.ba rbosa_lucia.pdf. Acesso em: 25 set. 2021.

BRASIL. Ministério das Relações Exteriores. Panorama da contribuição do Brasil para a difusão do Português. Brasília: FUNAG, 2021. Disponível em:

https://funag.gov.br/biblioteca-nova/produto/1-431-1. Acesso em: 25 set. 2021.

BULLA, Gabriela da Silva; KUHN, Tanara Zingano. Português como língua adicional no Brasil - perfis e contextos implicados. ReVEL na Escola, Porto Alegre, v. 18, n. 35, p. 128, 2020. Disponível em:

http://www.revel.inf.br/files/d0e7e22f8c5191e1009a4ca3dc37df2e .pdf. Acesso em: 25 set. 2021.

CARON, Monica Filomena; BRACCIALI, Márcia. Experiência de ensino de português brasileiro para indígenas e estrangeiros. Sociedade Internacional de Português Língua Estrangeira - SIPLE, [s. I.], v. 1, p. 1-9, 2010. Disponível em: http://assiple.org/revistasiple/. Acesso em: 25 set. 2021. 
CELPE-BRAS. Postos aplicadores credenciados. 2019. Disponível em: http://www.ufrgs.br/acervocelpebras/dados-celpe-bras/postos-aplicadorescredenciados-1/view. Acesso em: Acesso em 24 jul. 2021.

COLÓQUIO AÇÃO E REFLEXÃO EM PORTUGUÊS PARA ESTRANGEIROS, 11., 2020. São Carlos. Anais eletronicos...[...]. São Carlos: UFSCar, 2020. Disponível em: https://carpeufscar.wixsite.com/carpe2020. Acesso em: 20 de jul. 2021.

FURTOSO, Viviane Bagio. Onde estamos? Para onde vamos?: a pesquisa em português para falantes de outras línguas nas universidades brasileiras. In.: LUCAS, Patricia de Oliveira; RODRIGUES, Rosana Ferrareto Lourenço (org.). Temas e rumos nas pesquisas em linguística (aplicada): questões empíricas, éticas e práticas. Campinas: Pontes, 2015, p. 153-195.

GÓMEZ, Marina Ayumi Izaki. Saberes docentes e desafios no ensino de português língua estrangeira na atuação de professores em formação. 2018. Tese (Doutorado em Linguística) - Universidade Federal de São Carlos, São Carlos, 2018. Disponível em: https://repositorio.ufscar.br/handle/ufscar/10133. Acesso em: 25 set. 2021.

MORILAS, Luciana Romano. Português para adolescentes coreanos: uma experiência no ensino de português como LE. Disponível em:

http://www.gel.hospedagemdesites.ws/estudoslinguisticos/volumes/32/ht m/comunica/ci147.htm. Acesso em: 25 set. 2021.

ROCHA, Nildicéia Aparecida. O ensino de Português língua estrangeira no Brasil: ontem e hoje. Linguagens - Revista de Letras, Artes e Comunicação, Blumenau, v. 13, n. 1, p. 101-114, jan./abr. 2019. Disponível em:

https://proxy.furb.br/ojs/index.php/linguagens/arti

cle/view/8401. Acesso em: 25 set. 2021.

SCARAMUCCI, Matilde Virginia Ricardi; BIZON, Ana Cecília Cossi. (org.). Formação inicial e continuada de professores de Português Língua Estrangeira/Segunda Língua no Brasil. Araraquara: Letraria, 2020.

UNIVERSIDADE FEDERAL DE SÃO CARLOS - UFSCar. Apresentação. São Carlos: UFSCar, 2018. Disponível em: https://www2.ufscar.br/a-ufscar/apresentacao. Acesso em: 10 jul. 2021.

UNIVERSIDADE FEDERAL DE SÃO CARLOS - UFSCar. Instituto de Línguas da UFSCar. Projeto Político Pedagógico. São Carlos: UFSCar, 2020. Disponível em: https://www.institutodelinguas.ufscar.br/pt-br/normas. Acesso em: 25 set. 2021.

UNIVERSIDADE FEDERAL DE SÃO CARLOS - UFSCar. Portal de sistemas. São Carlos: UFSCar, [2021b]. Disponível em: https://www.portalsistemas.ufscar.br/. Acesso em: Acesso em 20 jul. 2021.

UNIVERSIDADE FEDERAL DE SÃO CARLOS - UFSCar. Pró-Reitoria de Extensão. Portal da transparência. São Carlos: UFSCar, [2021a]. Disponível em:

https://proexweb.ufscar.br/servicos/transparencia/. Acesso em: 24 de jul. 2021.

UNIVERSIDADE FEDERAL DE SÃO CARLOS - UFSCar. Sobre o RI UFSCar. São Carlos: 
UFSCar, [2021c]. Disponível em: https://repositorio.ufscar.br/. Acesso em: 05 ago. 2021.

VIANA, Nelson. Eventos da SIPLE em perspectiva. [S. I.]: SIPLE , 2019. Disponível em: https://sipleinternacional.wixsite.com/siple/eventos-da-siple-em-perspectiva. Acesso em: 05 ago. 2021.

Submetido em: 27 set. 2021. Aceito em: 24 out. 2021. 